\title{
BMJ
}

\section{Probiotics for treatment of acute diarrhoea in children: randomised clinical trial of five different preparations}

\author{
Roberto Berni Canani, assistant professor of paediatrics, ${ }^{1}$ Pia Cirillo, paediatrician, ${ }^{1}$ Gianluca \\ Terrin, paediatrician, ${ }^{1}$ Luisa Cesarano, paediatrician, ${ }^{1}$ Maria Immacolata Spagnuolo, paediatrician, ${ }^{1}$ \\ Anna De Vincenzo, paediatrician, ${ }^{1}$ Fabio Albano, paediatrician, ${ }^{1}$ Annalisa Passariello, paediatrician, \\ Giulio De Marco, paediatrician, ${ }^{1}$ Francesco Manguso, consultant physician in gastroenterology, ${ }^{2}$ \\ Alfredo Guarino, professor of paediatrics ${ }^{1}$
}

\section{${ }^{1}$ Department of Paediatrics, University of Naples Federico II, Naples, Italy \\ ${ }^{2}$ Department of Clinical and Experimental Medicine, University of Naples Federico II \\ Correspondence to: A Guarino alfguari@unina.it \\ do:10.1136/bmj.39272.581736.55}

\section{ABSTRACT}

Objective To compare the efficacy of five probiotic preparations recommended to parents in the treatment of acute diarrhoea in children.

Design Randomised controlled clinical trial in collaboration with family paediatricians over 12 months. Setting Primary care.

Participants Children aged 3-36 months visiting a family paediatrician for acute diarrhoea.

Intervention Children's parents were randomly assigned to receive written instructions to purchase a specific probiotic product: oral rehydration solution (control group); Lactobacillus rhamnosus strain GG; Saccharomyces boulardii; Bacillus clausii; mix of $L$ delbrueckii var bulgaricus, Streptococcus thermophilus, $L$ acidophilus, and Bifidobacterium bifidum; or Enterococcus faecium SF68.

Main outcome measures Primary outcomes were duration of diarrhoea and daily number and consistency of stools. Secondary outcomes were duration of vomiting and fever and rate of admission to hospital. Safety and tolerance were also recorded.

Results 571 children were allocated to intervention. Median duration of diarrhoea was significantly shorter ( $P<0.001$ ) in children who received $L$ rhamnosus strain GG (78.5 hours) and the mix of four bacterial strains (70.0 hours) than in children who received oral rehydration solution alone (115.0 hours). One day after the first probiotic administration, the daily number of stools was significantly lower $(\mathrm{P}<0.001)$ in children who received $L$ rhamnosus strain $\mathrm{GG}$ and in those who received the probiotic mix than in the other groups. The remaining preparations did not affect primary outcomes. Secondary outcomes were similar in all groups.

Conclusions Not all commercially available probiotic preparations are effective in children with acute diarrhoea. Paediatricians should choose bacterial preparations based on effectiveness data.

Trial registration number Current Controlled Trials ISRCTN56067537.

\section{INTRODUCTION}

The management of acute diarrhoea consists of the replacement of lost fluid with glucose-electrolyte oral rehydration solution. This solution, however, reduces neither the severity nor the duration of diarrhoea. The search for such agents started over 20 years ago. ${ }^{1}$ Probiotics, defined as micro-organisms that exert beneficial effects on human health when they colonise the bowel, have been proposed as adjunctive therapy in the treatment of acute diarrhoea. ${ }^{2}$ Several microorganisms are effective in reducing the severity and duration of acute diarrhoea in children: Lactobacillus rhamnosus (formerly "Lactobacillus casei strain GG" or "Lactobacillus GG"), L plantarum, several strains of bifidobacteria, Enterococcus faecium SF68, the yeast Saccharomyces boulardii, and preparations containing a mix of strains. $^{2-7}$ Several trials with probiotic preparations have been conducted in different settings and with different end points. Meta-analyses of probiotic efficacy, including a Cochrane review, are also available. ${ }^{2-10}$ Few of these studies, however, meet the criteria of properly controlled trials. ${ }^{10}$

In a recent study of Italian children with diarrhoea, probiotics were the most commonly prescribed treatment. ${ }^{11}$ With the increasing availability and widespread use of probiotics, it is important to identify the most effective preparations. We evaluated the efficacy of five probiotic preparations for the treatment of acute diarrhoea in children.

\section{METHODS}

The study was a prospective single blind randomised controlled trial in which parents of children with acute diarrhoea received written instructions to purchase a specific brand of probiotic. The trial was performed in collaboration with family paediatricians, who in the Italian public health system care for children up to 12 years of age. We discussed the study design with six family paediatricians in three meetings. Diarrhoea was defined as three or more outputs of loose or liquid stools a day. Eligible children were those aged 3-36 months who were seen in paediatricians' offices from October 1999 to 


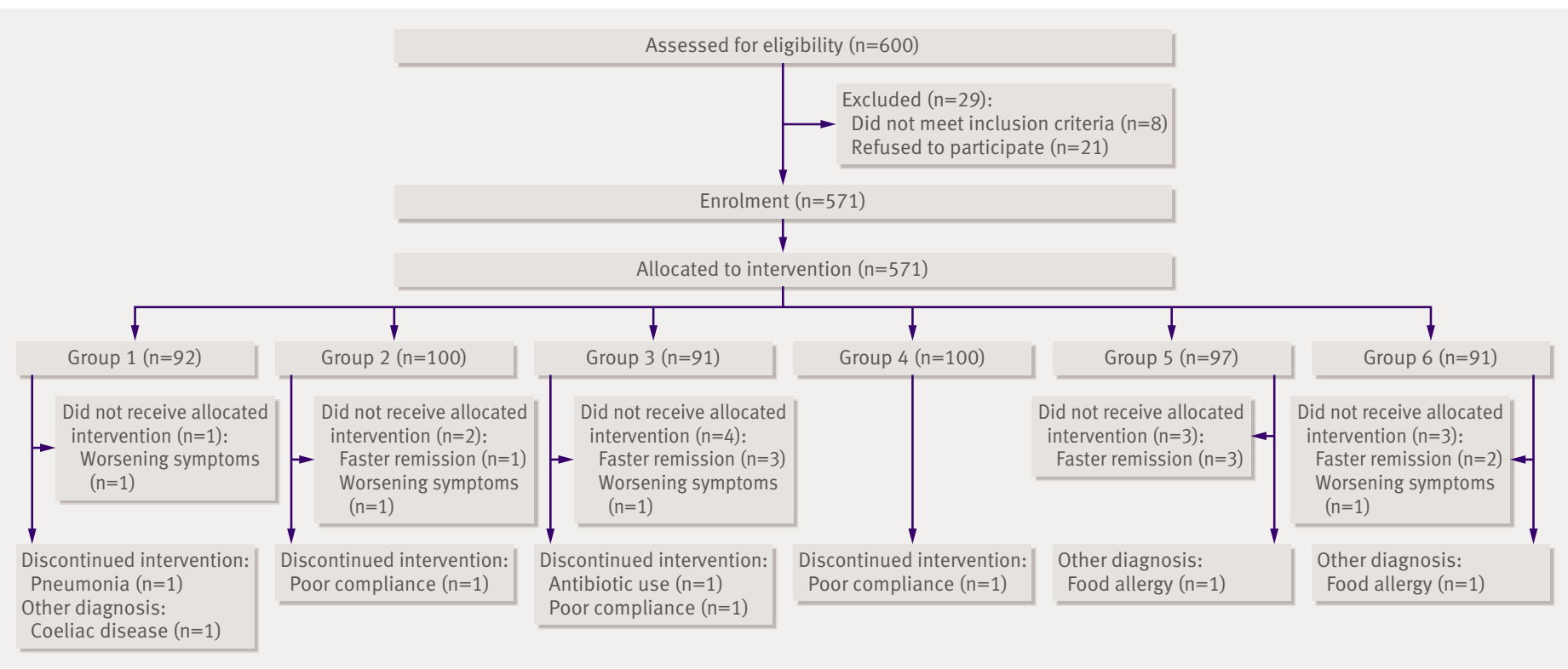

Flow of participants through trial of probiotic preparations for treatment of childhood acute diarrhoea

September 2000 because of diarrhoea. We included in the study all children with diarrhoea lasting less than 48 hours for whom parents gave informed consent. Exclusion criteria were malnutrition as judged by the ratio of weight to height, clinical signs of severe dehydration, clinical signs of coexisting acute systemic illnesses (meningitis, sepsis, pneumonia), immunodeficiency, underlying severe chronic diseases, cystic fibrosis, food allergy or other chronic gastrointestinal diseases, use of probiotics in the previous three weeks, use of antibiotics or any antidiarrhoeal medication in the previous three weeks and during the study, and poor compliance (defined by administration of less than four doses of the study medication).

All children were given oral rehydration solution for three to six hours and then fed with full strength formula containing lactose or cows' milk, depending on age. ${ }^{12-14}$ Microbiological investigation was performed only if required for specific clinical reasons. Children were also randomised to oral rehydration alone; Lactobacillus GG; $S$ boulardii;Bacillus clausii; mix of $L$ delbrueckii var bulgaricus, Streptococcus thermophilus,
$L$ acidophilus, and Bifidobacterium bifidum; or E faecium strain SF68. Table 1 shows the main characteristics of the probiotic preparations.

Patients were allocated to each group according to a computer generated randomisation list. Random allocation was made in blocks of six to obtain groups of similar size. The sequence was concealed until treatments were assigned. The researchers responsible for enrolling the patients allocated the next available number on entry into the trial, and the parent of each child received written instructions to purchase the assigned probiotic product.

Probiotic preparations were prescribed for five days and administered orally in $20 \mathrm{ml}$ water according to the manufacturers' instructions. All the probiotic products used in this study were available only in pharmacies and had a similar brand image and price. Each pack of probiotic preparation was sufficient for the entire therapeutic course. The group of children who received only oral rehydration served as controls.

The primary outcome measures were the total duration of diarrhoea and the number of stools a

\begin{tabular}{|c|c|c|c|c|c|}
\hline Groups & Micro-organisms & Strains & Dose (twice daily) & Brand* & Price $(€)$ \\
\hline 2 & Lactobacillus casei & Rhamnosus GG & $6 \times 10^{9} \mathrm{CFU} /$ dose & Dicoflor 60 & 10.50 \\
\hline 3 & Saccharomyces boulardii & S boulardii It & $5 \times 10^{9}$ live micro-organisms/dose & Codex $†$ & 8.50 \\
\hline 4 & Bacillus clausii & O/C84, N/R84, T84, SIN84 & $10^{9} \mathrm{CFU} /$ dose & Enterogermina† & 6.50 \\
\hline 5 & $\begin{array}{l}\text { L delbrueckii var bulgaricus, } L \\
\text { acidophilus, Streptococcus } \\
\text { thermophilus, B bifidum }\end{array}$ & $\begin{array}{l}\text { LMG-P17550, LMG-P } 17549 \text {, } \\
\text { LMG-P 17503, LMG-P } 17500\end{array}$ & $\begin{array}{l}10^{9} \mathrm{CFU}, 10^{9} \mathrm{CFU}, 10^{9} \mathrm{CFU} \\
5 \times 10^{8} \mathrm{CFU} / \text { dose }\end{array}$ & Lactogermina† & 10.50 \\
\hline 6 & Enterococcus faecium & SF 68 & $7.5 \times 10^{7} \mathrm{CFU} /$ dose & Bioflorin† & 10.50 \\
\hline
\end{tabular}

$\mathrm{CFU}=$ colony forming units.

*All sold in coloured cardboard boxes.

tComposition, brand name, and costs of these probiotic preparations have changed since study ended. 
Table 2 | Baseline features of children with diarrhoea allocated to study treatments

\begin{tabular}{|c|c|c|c|c|c|c|}
\hline & $1(n=92)$ & $2(n=100)$ & $3(n=91)$ & $4(n=100)$ & $5(n=97)$ & $6(n=91)$ \\
\hline No (\%) of boys & $41(44)$ & $60(60)$ & $44(48)$ & $49(49)$ & $49(50)$ & $39(42)$ \\
\hline Median (IQR) age (months) & $17(11-28)$ & $20(13-25)$ & $18(10-27)$ & $19(10-24)$ & $16(10-28)$ & $15(8-22)$ \\
\hline Median (IQR) weight (kg) & $11.9(9.9-12.7)$ & $12.1(9.1-13.2)$ & $11.5(9.2-14.0)$ & $12.3(9.4-13.4)$ & $12.7(9.5-14.2)$ & $12.2(10.3-13.5)$ \\
\hline \multicolumn{7}{|l|}{ Feeding (\%) } \\
\hline Breast milk & 13.5 & 11.7 & 13.3 & 10.0 & 13.4 & 17.9 \\
\hline Formula & 55.8 & 55.0 & 55.6 & 60.2 & 46.2 & 43.6 \\
\hline Cows' milk & 30.8 & 33.3 & 31.1 & 29.8 & 40.5 & 38.5 \\
\hline $\begin{array}{l}\text { Median (IQR) duration of diarrhoea } \\
\text { before treatment (hours) }\end{array}$ & $9(4-13)$ & $10(5-18)$ & $11(6-18)$ & $10(4-15)$ & $9(5-17)$ & $10(5-16)$ \\
\hline
\end{tabular}

$\mathrm{IQR}=$ interquartile range.

day and their consistency. Duration of diarrhoea was the time in hours from the first to the last abnormal (loose or liquid) stools preceding a normal stool output. Stool consistency was evaluated through a score system, as previously described, ${ }^{15}$ and faeces were graded as 1 (normal), 2 (loose), 3 (semiliquid), and 4 (liquid). Secondary outcome measures were the incidence and median duration of vomiting, fever $\left(>37.5^{\circ} \mathrm{C}\right)$, and the number of hospital admissions in each group. We also investigated safety and tolerability.

On enrolment we identified each child, determined the duration and severity of diarrhoea, assessed associated clinical features (fever, vomiting, dehydration), and established nutritional status and previous treatment. Parents received a coded reporting form on which to record clinical data. They were instructed to record daily the number of faecal outputs and their consistency, the type and doses of probiotic preparation taken by the child, the presence of vomiting and fever, any necessity for hospital admission, and all adverse events.

The study was performed according to a multicentre single blind and controlled design. Because of the problems of performing a double blind study of commercially available products in a large population, we used the third party blind observer method to assess efficacy. To ensure unbiased assessment, the family paediatricians, who were in charge of treatment allocation, gave written instructions to the parents to purchase a brand of probiotic and verified compliance on the reporting form, whereas the investigators collecting the reporting forms were blinded to the assigned treatment. All reporting forms were delivered to the coordinating centre at the Department of Paediatrics for analysis. This procedure was applied in previous studies of the efficacy of antidiarrhoeal treatments. ${ }^{1516}$ All parents of enrolled children gave informed consent.

\section{ESTIMATE OF SAMPLE SIZE}

To obtain the required power $(95 \%$, type 1 error $=0.05$, two tailed test) we needed 45 participants in each group. This estimate assumes a mean difference in duration of diarrhoea of 24 hours between the treated and control children (corresponding to means of 120 and 96 hours) with an SD of 30 hours within the group. This computation was based on the results of a preliminary open trial. ${ }^{15}$ To investigate the secondary outcomes, we doubled the number of patients. Our estimation of sample size allowed for a drop out of up to $10 \%$.

\section{STATISTICAL ANALYSIS}

A statistician blind to allocation performed the statistical analyses. We used $\chi^{2}$ test for categorical variables and Mann-Whitney U test for continuous variables by analysing differences between group 1 and groups 2-6. All analyses were conducted on an intention to treat basis with SPSS version 15.0.0 for Windows (SPSS, Chicago, IL).

\begin{tabular}{|c|c|c|c|c|}
\hline Group & Treatment & $\begin{array}{l}\text { Median (IQR) duration } \\
\text { (hours) }\end{array}$ & $\begin{array}{l}\text { Estimated difference } \\
\qquad(95 \% \mathrm{Cl})^{\star}\end{array}$ & $\mathrm{P}$ value $†$ \\
\hline 1 & Oral rehydration solution alone & $115.5(95.2-127)$ & - & - \\
\hline 2 & Lactobacillus casei subsp rhamnosus GG & $78.5(56.5-104.5)$ & $-32(-41$ to -23$)$ & $<0.001$ \\
\hline 3 & Saccharomyces boulardii & $105.0(90-104.5)$ & $-5(-13$ to 5$)$ & 0.38 \\
\hline 4 & Bacillus clausii & $118.0(95.2-128.7)$ & $1(-7$ to 8$)$ & 0.76 \\
\hline 5 & $\begin{array}{l}\text { L delbrueckii var bulgaricus, } L \text { acidophilus, } \\
\text { Streptococcus thermophilus, } B \text { bifidum }\end{array}$ & $70.0(49-101)$ & $-37(-47$ to -25$)$ & $<0.001$ \\
\hline 6 & Enterococcus faecium SF 68 & $115.0(89-144)$ & $2(-5$ to 11$)$ & 0.61 \\
\hline
\end{tabular}




\begin{tabular}{|c|c|c|c|c|c|c|c|c|}
\hline \multirow[b]{2}{*}{ Group } & \multirow[b]{2}{*}{ Treatment } & \multicolumn{7}{|c|}{ Day } \\
\hline & & 1 & 2 & 3 & 4 & 5 & 6 & 7 \\
\hline 1 & Oral rehydration solution alone & $5(4-6)$ & $5(4-7)$ & $4(4-6)$ & $4(3-5)$ & $3(2-4)$ & $2(2-3)$ & $2(1-3)$ \\
\hline 2 & Lactobacillus casei subsp rhamnosus GGT & $6(4-6)$ & $4(4-6)^{*}$ & $4(3-5) \dagger$ & $3(2-4)^{*}$ & $2(2-3) \ddagger$ & $2(2-3)$ & $2(1-2)$ \\
\hline 3 & Saccharomyces boulardii & $5(4-6)$ & $5(4-7)$ & $4(3-6)$ & $4(3-5)$ & $3(2-4)$ & $2(2-3)$ & $2(1-3)$ \\
\hline 4 & Bacillus clausii & $6(4-6)$ & $5(4-7)$ & $4(4-7)$ & $4(3-5)$ & $3(2-4)$ & $2(2-3)$ & $2(1-2)$ \\
\hline 5 & $\begin{array}{l}\text { Ldelbrueckii var bulgaricus, L acidophilus, } \\
\text { Streptococcus thermophilus, B bifidum }\end{array}$ & $6(4-6)$ & $4(4-6)^{\star}$ & $3(3-4.5)^{\star}$ & $3(2-4)^{*}$ & $2(2-3) \S$ & $2(2-3)$ & $2(1-2)$ \\
\hline 6 & Enterococcus faecium SF 68 & $5(4-6)$ & $5(4-7)$ & $4(4-6)$ & $4(3-5)$ & $3(2-4)$ & $2(2-3)$ & $2(1-2)$ \\
\hline
\end{tabular}

$\mathrm{IQR}=$ interquartile range.

${ }^{*} \mathrm{P}<0.001, \dagger \mathrm{P}=0.001, \ddagger \mathrm{P}=0.003$, or $\S \mathrm{P}=0.002 \mathrm{v}$ oral rehydration solution alone at same time point by Mann-Whitney $\mathrm{U}$ test.

ๆOn days $2,3,4$, and 5 estimated difference $(95 \% \mathrm{Cl})$ compared with oral rehydration solution alone was $-1(-1$ to 0$)$.

\section{RESULTS}

The figure shows the flow of children through the study. A total of 600 children with acute diarrhoea were eligible for inclusion: 29 were excluded and 571 were randomised to receive intervention and contributed data to the intention to treat analysis.

The baseline features of the patients enrolled in the six groups were similar (table 2). The total duration of diarrhoea was significantly lower in children receiving Lactobacillus GG (group 2) and in those receiving the bacterial mix (group 5) than in patients receiving oral rehydration alone (group 1) (table 3). The three other probiotic preparations had no effect on diarrhoea, and the duration of diarrhoea in groups 3,4 , and 6 was similar to that in the group receiving only oral rehydration (table 3). Daily stool output was significantly lower $(\mathrm{P}<0.001)$ in groups 2 and 5 (table 4$)$, starting the day after the first probiotic administration. Median stool outputs per day did not differ between groups 2 and 5 (table 4). Stool consistency, as judged by the scoring system, differed significantly $(\mathrm{P}<0.001)$ with preparations 2 and 5 versus the other groups (table 5). The median daily scores did not differ between groups 2 and 5 (table 5). Microbiological investigations were requested in only a few instances, and the results did not provide useful information.

None of the secondary outcome measures we evaluated was significantly modified in children receiving probiotic preparations or in the control group (table 6). All parents purchased the product indicated by the paediatrician. The probiotic preparations included in the study were well received by nearly all the children, and no adverse events were observed.

\section{DISCUSSION}

\section{Main study findings}

In an evaluation of five probiotic preparations in children with diarrhoea we found substantial differences in efficacy. Two preparations reduced the duration and severity of diarrhoea, whereas the three others had no significant effect. A recent Cochrane meta-analysis of 23 randomised controlled trials found mild therapeutic benefit from probiotics that was generally reproducible regardless of organism. ${ }^{10}$ In the only comparative trial reported previously, three preparations were tested in 46 children. ${ }^{17}$

Acute infectious diarrhoea is still a major cause of childhood morbidity. It is also a source of anxiety to families of affected children and represents a heavy economic burden for families and for society as a whole. ${ }^{1819}$ Drugs that affect intestinal motility, ion transport and adsorptive moieties, and living bacteria have been used in the attempt to reduce the duration of diarrhoea. ${ }^{18-20}$ Probiotics have progressively gained in credibility for the treatment of diarrhoeal diseases. ${ }^{22122}$ In most countries, however, micro-organisms purported to have probiotic properties are considered to be food additives rather than drugs. Consequently, only safety features and not proof of efficacy are required for marketing. ${ }^{23}$ In addition, the term

\begin{tabular}{|c|c|c|c|c|c|c|c|c|}
\hline \multirow[b]{2}{*}{ Group } & \multirow[b]{2}{*}{ Treatment } & \multicolumn{7}{|c|}{ Day } \\
\hline & & 1 & 2 & 3 & 4 & 5 & 6 & 7 \\
\hline 1 & Oral rehydration solution alone & $3(3-3)$ & $3(2-3)$ & $2(2-3)$ & $2(1-3)$ & $2(1-2)$ & $1(1-1)$ & $1(1-1)$ \\
\hline 2 & Lactobacillus casei subsp rhamnosus GG & $3(3-3)$ & $2(2-3) \dagger$ & $1(1-2) \dagger$ & $1(1-2) \dagger$ & $1(1-1) \dagger$ & $1(1-1)$ & $1(1-1)$ \\
\hline 3 & Saccharomyces boulardii & $3(3-3)$ & $3(2-3)$ & $2(2-3)$ & $2(2-3)$ & $2(1-2)$ & $1(1-2)$ & $1(1-1)$ \\
\hline 4 & Bacillus clausii & $3(3-3)$ & $3(2-3)$ & $2(2-3)$ & $2(2-3)$ & $2(1-2)$ & $1(1-2)$ & $1(1-1)$ \\
\hline 5 & $\begin{array}{l}\text { L delbrueckii var bulgaricus, L acidophilus, } \\
\text { S thermophilus, B bifidum } \ddagger\end{array}$ & $3(3-3)$ & $2(2-3) \S$ & $1(1-2) \dagger$ & $1(1-2) \dagger$ & $1(1-1) \dagger$ & $1(1-1)$ & $1(1-1)$ \\
\hline 6 & Enterococcus faecium SF 68 & $3(3-3)$ & $3(2-3)$ & $2(2-3)$ & $2(1-2)$ & $2(1-2)$ & $1(1-2)$ & $1(1-1)$ \\
\hline
\end{tabular}

$\mathrm{IQR}=$ interquartile range.

*Stool consistency score system: 1=normal; 2=loose; 3=semiliquid; $4=$ =liquid. ${ }^{15}$

$\dagger \mathrm{P}<0.001$ or $\S \mathrm{P}=0.001 \mathrm{v}$ oral rehydration solution alone at same time point by Mann-Whitney $\mathrm{U}$ test.

†On days 2 and 5 estimated difference $(95 \% \mathrm{Cl})$ compared with oral rehydration solution alone was $0(-1$ to 0$)$; on days 3 and 4 it was -1 ( -1 to 0$)$. 
Table 6 | Secondary outcomes in children with diarrhoea according to treatment group

\begin{tabular}{|c|c|c|c|c|c|c|c|}
\hline Group & 1 & 2 & 3 & 4 & 5 & 6 & $P$ value \\
\hline No (\%) admitted to hospital & $4(4.3)$ & $1(1.0)$ & $4(4.4)$ & $4(4.0)$ & $2(2.1)$ & $4(4.4)$ & $0.68^{*}$ \\
\hline \multicolumn{8}{|l|}{ Fever: } \\
\hline No (\%) of children & $32(34.8)$ & $30(30.0)$ & $27(29.7)$ & $29(29.0)$ & $30(30.9)$ & $36(39.6)$ & $0.61^{*}$ \\
\hline Median (IQR) duration (days) & $2(1-2)$ & $1(1-2)$ & $2(1.7-2)$ & $2(1-3)$ & $1(1-3)$ & $2(1-3)$ & $0.10 \dagger$ \\
\hline \multicolumn{8}{|l|}{ Vomiting: } \\
\hline No (\%) of children & $34(37.0)$ & $31(31.0)$ & $24(26.4)$ & $32(32.0)$ & $34(35.1)$ & $36(39.6)$ & $0.47^{\star}$ \\
\hline Median (IQR) duration (days) & $2(1-2)$ & $1(1-2)$ & $2(1.0)$ & $1.5(1-2)$ & $1(1-2)$ & $1.5(1-2)$ & $0.25 \dagger$ \\
\hline $\begin{array}{l}\text { IQR=interquartile range. } \\
{ }^{*} X^{2} \text { test. } \\
\text { †Mann-Whitney } U \text { test. }\end{array}$ & & & & & & & \\
\hline
\end{tabular}

"probiotic" is often improperly used and information about specific probiotic properties of the strains contained in the products are not exhaustive. ${ }^{24} \mathrm{We}$ did not conduct a qualitative and quantitative study of the microbial content of the probiotic preparations in this trial because we wanted to carry out a field trial of the clinical effectiveness of commercially available probiotic products that had been prescribed by the paediatrician.

Lactobacillus GG was associated with a shorter duration of diarrhoea, which was not unexpected because proof of efficacy of this strain has been obtained in children in hospitals and outpatients in both industrialised and developing countries. ${ }^{21525-27}$ The results that we obtained with Lactobacillus GG closely resembled those obtained in a similar setting with the same strain. ${ }^{15}$ The other effective preparation was a mix of four strains. A formula with St thermophilus and B bifi$d u m$, two of the four bacterial species in the effective preparation, protected against diarrhoea in chronically sick children aged below 24 months. ${ }^{5}$ The three other preparations we evaluated had no or little clinical effect. This was unexpected in the case of $S$ boulardii because a previous controlled trial showed it to be beneficial in children admitted to hospital for diarrhoea ${ }^{28}$ - that is, with a more severe condition than the mild to moderate diarrhoea in the children in our trial — which could explain the different results obtained in the two studies. A previous trial with Streptococcus faecium strain SF68 resulted in clinical improvement in children with diarrhoea associated with respiratory infection and treated with parenteral antibiotics, ${ }^{29}$ though it had no effect in adults with diarrhoea. ${ }^{30}$ Finally, the $B$ clausii preparation had no effect. None of the preparations had a significant effect on secondary outcomes, probably because of the relatively low incidence of fever, vomiting, and hospital admissions in our children. No side effects were recorded.

Diarrhoea in developed countries is usually self limiting, and active treatment is not generally recommended. Over the counter drugs or preparations, however, are widely used. We did not consider the cause of the diarrhoea. Probiotics are generally prescribed without a specific indication. All the children enrolled in our study were outpatients, and microbiological investigations were performed only in a few.
Based on the findings of a large study conducted in Italy, ${ }^{31}$ it is reasonable to assume that most of the children were affected by viral acute gastroenteritis.

\section{Possible confounding}

We cannot exclude the possibility that expectations of parents confounded our results. The brands investigated were among the most widely used probiotic preparations in Italy when the study was conducted. These products were not advertised in the press or on television, there were no remarkable differences in their brand image, and they were available only in pharmacies at the time of the study. Preconceptions within the general public about their efficacy are therefore unlikely. Similarly, in Italy it is unlikely that the public would perceive one micro-organism to be more effective than another. The lack of preconceptions about the efficacy of treatment seems to be supported by our finding that only one of the two most widely used probiotic brands in Italy was effective (group 2) whereas the other was not (group 4). A high or low cost might have affected expectations either positively or negatively, but parents were probably unaware of the comparative costs of the products investigated. From these observations, it seems unlikely that parents advised to purchase one product would have higher or lower expectations than parents assigned to purchase another product, though we cannot exclude this.

In conclusion, the efficacy of probiotic preparations for the treatment of childhood acute diarrhoea is related to the individual strains of bacteria. We believe that probiotic preparations should be classified as drugs, and physicians should select preparations for which evidence of efficacy, in a given clinical condition, is supported by solid data.

WHAT IS ALREADY KNOWN ON THIS TOPIC
$\begin{aligned} & \text { Several probiotic products are marketed in many European } \\ & \text { countries for the treatment of acute diarrhoea in children }\end{aligned}$
WHAT THIS STUDY ADDS
$\begin{aligned} & \text { The efficacy of probiotic preparations for the treatment of } \\ & \text { children with acute diarrhoea is related to the strain of } \\ & \text { bacteria }\end{aligned}$


We are grateful to Jean Ann Gilder for editing the text. The research was no sponsored by any pharmaceutical or food company, including yoghurt companies

Contributors: $\mathrm{RBC}$ and $\mathrm{AG}$ designed the study, coordinated the research team, and wrote the first draft of the report. PC, FA, LC, MIS, ADeV, and AP cared for the patients and contributed to the final version of the report. GDeM and GT performed the data analysis and FM contributed to the design of the study, developed the computer generated randomisation list, and performed statistical analyses. AG is guarantor.

Competing interests: None declared

Funding: None.

Ethical approval: Ethics committee of University of Naples Federico II.

Provenance and peer review: Non-commissioned; externally peer reviewed

1 Alam NH, Ashraf H. Treatment of infectious diarrhea in children Paediatr Drugs 2003;5:151-65.

2 Szajewska H, Setty M, Mrukowicz J, Guandalini S. Probiotics in gastrointestinal diseases in children: hard and not-so-hard evidence of efficacy. J Pediatr Gastroenterol Nutr 2006;42:454-75.

3 Isolauri E. Probiotics for infectious diarrhoea. Gut 2003;52:436-7.

4 Davidson GP, Butler RN. Probiotics in intestinal disorders. Curr Opin Pediatr 2000:12:477-81.

5 Saavedra JM, Bauman NA, Oung I, Perman JA, Yolken RH. Feeding of Bifidobacterium bifidum and Streptococcus thermophilus to infants in hospital for prevention of diarrhoea and shedding of rotavirus. Lancet 1994:344:1046-9.

6 Tankanow RM, Ross MB, Ertel IJ, Dickinson DG, McCormick LS, Garfinkel JF. A double-blind, placebo controlled study of the efficacy of Lactinex in the prophylaxis of amoxicillin-induced diarrhea. DICP 1990;24:382-4.

7 Elmer GW, Surawicz CM, McFarland LV. Biotherapeutic agents: a neglected modality for the treatment and prevention of selected intestinal and vaginal infections. JAMA 1996;275:870-6.

8 Huang JS, Bousvaros A, Lee JW, Diaz A, Davidson EJ. Efficacy of probiotic use in acute diarrhea in children: a meta-analysis. Dig Dis Sci 2002;47:2625-34.

9 Van Niel CW, Feudtner C, Garrison MM, Cristakis DA. Lactobacillus therapy for acute infectious diarrhea in children: a meta-analysis. Pediatrics 2002;109:678-84.

10 Allen SJ, Okoko B, Martinez E, Gregorio G, Dans LF. Probiotics for treating infectious diarrhoea. Cochrane Database Syst Rev 2004;(2) CD003048.

11 Fontana M, Zuin G, Pancheri P, Fusco F, Lambertini A, Berni Canani R, SIGEP Working Group on Intestinal Infections. Costs associated with outpatient diarrhoea in infants and toddlers: a nationwide study of the Italian Society of Paediatric Gastroenterology and Hepatology (SIGEP). Dig Liver Dis 2004:36:523-7.

12 Walker-Smith JA, Sandhu BK, Isolauri E, Banchini G, van Caillie-Bertrand M, Dias JA, et al. Guidelines prepared by ESPGAN working group on acute diarrhoea. Recommendations for feeding in childhood gastroenteritis. I Pediatr Gastroenterol Nutr 1997;24:619-20

13 ESPGAN Working Group on Acute Diarrhoea. Recommendations for composition of oral rehydration solutions for children of Europe. Pediatr Gastroenterol Nutr 1992;14:113-5.
14 Guarino A, Albano F. Guidelines for the approach to outpatient children with acute diarrhoea. Acta Paediatr 2001;90:1096-8.

15 Guarino A, Berni Canani R, Spagnuolo MI, Albano F, Di Benedetto L. Oral bacterial therapy reduces the duration of symptoms and of vira excretion in children with mild diarrhea. J Pediatr Gastroenterol Nutr 1997;25:516-9.

16 Guarino A, Canani RB, Russo S, Albano F, Canani MB, Ruggeri FM, et al. Oral immunoglobulins for treatment of acute rotaviral gastroenteritis. Pediatrics 1994;93:12-6.

17 Majamaa $\mathrm{H}$, Isolauri E, Saxelin M, Vesikari T. Lactic acid bacteria in the treatment of acute rotavirus gastroenteritis. J Pediatr Gastroenterol Nutr 1995;20:333-8.

18 Guandalini S. Treatment of acute diarrhea in the new millennium. J Pediatr Gastroenterol Nutr 2000;30:486-9.

19 Zimmerman CM, Bresee JS, Parashar UD, Riggs TL, Holman RC, Glass RI. Cost of diarrhea-associated hospitalizations and outpatient visits in an insured population of young children in the United States. Pediatr Infect Dis / 2001;20:14-9.

20 Farthing MJG. Novel targets for the pharmacotherapy of diarrhoea: a view for the millennium. J Gastroenterol Hepatol 2000;15:G38-45.

21 Reid G, Jass J, Sebulsky MT, McCormick JK. Potential uses of probiotics in clinical practice. Clin Microbiol Rev 2003;16:658-72.

22 Szajewska H, Hoekstra JH, Sandhu B, the working group on acute diarrhoea of the European Society for Paediatric Gastroenterology, Hepatology and Nutrition. Management of acute gastroenteritis in Europe and the impact of the new recommendations: a multicenter study. J Pediatr Gastroenterol Nutr 2000;30:522-7.

23 Young J. European Market developments in prebiotic- and probiotic containing foodstuffs. Br J Nutr 1998;80:S231-3.

24 Drago L, De Vecchi E, Nicola L, Colombo A, Gismondo MR. Microbiological evaluation of commercial probiotic products available in Italy. J Chemother 2004;16:463-7.

25 Oberhelman RA, Gilman RH, Sheen P, Taylor DN, Black RE, Cabrera L, et al. A placebo-controlled trial of Lactobacillus GG to prevent diarrhea in undernourished Peruvian children. J Pediatr 1999;134:15-20.

26 Saxelin M. Lactobacillus GG a human probiotic strain with thorough clinical documentation. Food Rev Int 1997;13:293-313.

27 Guandalini S, Pensabene L, Zikri MA, Dias JA, Casali LG, Hoekstra H, et al. Lactobacillus GG administered in oral rehydration solution to children with acute diarrhea: a multicenter European trial. J Pediatr Gastroenterol Nutr 2000;30:54-60.

28 Kurugol Z, Koturoglu G. Effects of Saccharomyces boulardii in children with acute diarrhoea. Acta Paediatr 2005;94:44-7.

29 Bellomo G, Mangiagli A, Nicastro L, Frigerio G. A controlled doubleblind study of SF68 strain as a new biological preparation for the treatment of diarrhoea in paediatrics. Curr Ther Res 1980;27:927-36.

30 Mitra AK, Rabbani GH. A double-blind, controlled trial of Bioflorin (Streptococcus faecium SF68) in adults with acute diarrhea due to Vibrio cholerae and enterotoxigenic Escherichia coli. Gastroenterology 1990;99:1149-52.

31 Caprioli A, Pezzella C, Morelli R, Giammanco A, Arista S, Crotti D, et al. Enteropathogens associated with childhood diarrhea in Italy. Pediat Infect Dis / 1996;15:876-83.

Accepted: 18 June 2007 